\title{
Pituitary resistance to thyroid hormone
}

INSERM

\section{Source}

INSERM. (1999). Orphanet: an online rare disease and orphan drug data base. Pituitary resistance to thyroid hormone. ORPHA:165994

Pituitary resistance to thyroid hormone is a rare, genetic thyroid disease, due to reduced pituitary gland responsiveness to thyroid hormone, characterized by mild to moderate hyperthyroidism in association with elevated circulating thyroid hormone levels, normal or elevated thyroid stimulating hormone, and no abnormalities of the pituitary gland on MRI. Patients present with diffuse large goiter, tachycardia, atrial fibrillation, weight loss and/or heat intolerance/perspiration, but no exophthalmos or anterior tibial mixedema. 